Absenteeism in the Public and the Private Sector: Does the Public Sector Attract High Absence Employees?

Arne Mastekaasa

University of Oslo

Department of Sociology and Human Geography

PO Box 1097 Blindern

N-0317 Oslo

Norway

arnema@sosgeo.uio.no 


\title{
Absenteeism in the Public and the Private Sector: Does the Public Sector Attract High Absence Employees?
}

\begin{abstract}
Evidence from many countries show that public sector employees have considerably higher rates of absenteeism than have private sector employees. Based on regression analyses of a large probability sample of the Norwegian population, this article shows that most of the sector difference in long-term absence can be accounted for by taking into consideration the socio-demographic characteristics of the workforce and the occupational composition in the two sectors. A clear sector difference in short-term absenteeism cannot be accounted for in this way. A direct effect of the working or employment conditions in the two sectors is also not a likely explanation, since workers who switch between the sectors are not more absent when they are in the public than when they are in the private sector. Thus, the high level of short-term absenteeism in the public sector seems to be due to a selection of absence prone individuals to the sector. Since motivational factors are likely to be relatively more important for short-term than for long-term, these findings indicate that lower work attendance motivation in among public sector employees may be the main driver. These patterns are consistent with an economic explanation in which people with low attendance motivation select to the public sector, since the work attendance incentives are weaker there. The degree to which the results are compatible with the theory Public Service Motivation (PSM) is also discussed.
\end{abstract}




\section{Absenteeism in the Public and the Private Sector: Does the Public}

\section{Sector Attract High Absence Employees?}

\section{Introduction}

Evidence from a number of countries shows that the level of absenteeism is higher-and often much higher-in the public than in the private sector. The UK labor force surveys indicate that the level of absence from work is 60 percent higher in the public sector ${ }^{1}$, and the difference is similar in Canada (Uppal and LaRochelle-Côté 2013) and even larger in Denmark (84 percent). ${ }^{2}$ Higher public sector absenteeism is reported also for the Netherlands (31 percent) $)^{3}$ and for Germany (10 to 17 percent) (Böhm and Riedel 2013; Riphahn 2004). In the US, the incidence of absenteeism is 40 percent higher in the public sector than in private services (D’Amuri 2017).

The large differences in absenteeism raise the question of whether the public and the private sector attract different kinds of workers. The sector differences seem to fit well with the long-standing popular stereotype of public employees as lazy and self-interested (Van de Walle 2004). They are also in line with common approaches to absenteeism in economics (Brown and Sessions 1996). A basic assumption in these economic approaches is that people generally prefer non-work to work, and that the amount of absence depends on how strong the work attendance incentives are. Since the incentives are weaker in the public sector (Bossaert 2005; Kearney and Mareschal 2014), it is rational for individuals with strong preferences for leisure to choose the public sector (Delfgaauw and Dur 2008; Pfeifer 2013). High absenteeism

\footnotetext{
${ }^{1}$ http://www.ons.gov.uk/ons/dcp171776_353899.pdf (2013 figures).

${ }^{2}$ http://www.statistikbanken.dk/10322 (2015 figures).

${ }^{3}$ http://www.eurofound.europa.eu/observatories/eurwork/comparative-information/nationalcontributions/netherlands/absence-from-work-netherlands. Statistics are for the period 2005-2008.
} 
in the public sector can therefore be explained in terms of negative selection. ${ }^{4}$

An explanation in terms of negative selection to the public sector may seem difficult to reconcile with common assumptions in public administration research and in particular with the theory of Public Sector Motivation (PSM) (Perry and Wise 1990; Perry, Hondeghem, and Wise 2010; Polidori and Teobaldelli 2013). In PSM theory the focus is rather on positive selection, as individuals with high levels of pro-social motivation are assumed to have a preference for public sector employment (see, e.g., Leisink 2008; Wright, Hassan and Christensen 2017). Since work attendance is a prerequisite for doing work that benefits other people or the society at large, a selection in terms of PSM should be expected to contribute to lower public sector absenteeism (Wright, Hassan and Christensen 2017).

However, other interpretations of the sector differences in absenteeism are possible. In the first place, it is not obvious that the sector difference in absenteeism should be explained in terms of incentives and motivation. An alternative explanation is that it is driven by sector differences in employee health or more generally in the ability to attend work (Steers and Rhodes 1978). In many countries the public sector has, e.g., more elderly employees (Eurofound 2012) and a higher proportion of women (Anghel, de la Rica, and Dolado 2011), two groups with relatively high absenteeism levels that are likely to be at least in part healthrelated (Uppal and LaRochelle-Côté 2013). In addition, health may itself be a factor influencing sector of employment, if employees believe, e.g., that public sector employment is

\footnotetext{
${ }^{4}$ In line with typical usage in methodological discussions, the term "selection” encompasses all processes leading to an over- or underrepresentation in a given location of people with particular characteristics, e.g. an overrepresentation of absence prone individuals in the public sector (Heckman and Robb 1985). It thus includes differential movement both into and out of the public sector and self-selection as well as hiring and firing by employers. The selection is labeled as "negative” if it contributes to an arguably negative outcome, such as a high level of absenteeism.
} 
easier to combine with health problems or if the public sector is more accepting of individuals with such problems.

Secondly, the sector difference in absenteeism may not be a matter of selection effects at all. Another possibility is that it is caused by differences in the employment and working conditions to which private and public employees are exposed (i.e., it may be situational rather than predispositional). In the following, I shall refer to these influences as direct sector effects, as they do not work via the selection of employees to the two sectors. As there is more manual work in the private sector and more administrative and office work in the public sector, it might be difficult to see why work in the public sector should be less healthy than work in the private sector. However, there may be important stressors that are more common in the public sector, such as those associated with emotional labor (Grandey and Melloy 2017; Sloan 2014) or red tape (Coursey and Pandey 2007; Giauque, Anderfuhren-Biget, and Varone 2013). Other characteristics of public sector organizations may also be relevant, for instance that they are on average larger than private sector organizations (Barmby and Stephan 2000).

The aim of this paper is to examine whether at least part of the sector difference in absenteeism can be explained by selection to the public sector of employees with relatively low attendance motivation. To do this, I use data from the Norwegian Labor Force Survey (LFS) augmented with administrative data on medically certified absence. Two types of analyses are carried out. The first of these consists of standard cross-sectional analyses with various sets of control variables. To address limitations in these analyses, the second type of analysis utilizes longitudinal information to compare employees who switch between the sectors at least once during a ten-year period with those who are stably employed in either the private or the public sector.

In the cross-sectional analyses, I control for two sets of variables. Age, gender and 
level of education make up one set. These variables are all important determinants of health (Conti, Heckman and Urzua 2010; Knesebeck, Verde and Dragano 2006; Oksuzyan et al. 2008), and it is important to assess whether sector differences in absenteeism are only a matter of the differential age, gender and educational composition of the private and public workforces. To address the possibility that higher absenteeism in the public sector might be driven by differences in employment or working conditions, the second set of control variables consists of organizational size and more than 300 detailed occupational categories. I thus essentially compare employees who work in organizations of the same size and who do the same kind of work (e.g. personnel administration, computer programming, nursing).

These control variable analyses have obvious limitations. In the first place, there may be systematic health differences between the public and private sector workforces beyond those that can be accounted for by differential composition in terms of age, gender and education. I therefore carry out separate analyses for short-term and long-term absence, under the assumption that short-term absence is more strongly related to motivation (Ferrie et al., 2009; Vahtera, Pentti and Kivimäki 2004). If inclusion of the control variables reduces or even eliminates the estimated sector difference in long-term but not in short-term absenteeism, the argument that the latter is more a matter of motivation than of health is strengthened.

A second problem with the control variable analyses is that sector differences in absenteeism may well be driven by employment or working conditions other than those captured by control for organizational size and detailed occupation. This problem is addressed in the second type of analysis, viz. the comparison of sector switchers and non-switchers. Within the group of switchers, there should be no predispositional difference between those who are currently in the private and those in the private sector, since over time these are people who work in both sectors. Any sector difference within this group should therefore be 
the outcome of direct effects of current sector of employment and not selection. Within the group of non-switchers, on the other hand, the difference in absenteeism between public and private sector employees should reflect both the effects of the current sector of employment and the selection of more absence prone employees to one of the sectors than to the other. (For a similar argument with regard to sector differences in overtime work, see Gregg et al. 2011.)

\section{Conceptual issues}

\subsection{Absenteeism}

In an influential article, Steers and Rhodes (1978) argued that absence from work (or its obverse, work attendance) should be seen as a function of both the ability to attend and the motivation to attend. Illness and accidents are cited as prime factors affecting ability, along with family responsibilities and transportation problems. Ability to attend is also likely to depend on job or occupational characteristics; a construction worker can hardly do her job with a broken leg, but an office worker may be able to do so. ${ }^{5}$

It is generally assumed that long-term absence periods are primarily determined by a lack of ability to attend, and short-term absences by low attendance motivation; in other words, the former are seen as largely involuntary or unavoidable and the latter as largely voluntary or avoidable (see, e.g., Hackett and Guion 1985). This is particularly the case when long-term, but not short-term absence requires certification from a physician, as is the case in many countries. In line with the assumption that long-term absence is more strongly related to illness, long-term (but not short-term) absence has been found to predict survival (Ferrie et al., 2009; Vahtera, Pentti and Kivimäki 2004). This is not to say that short-term absence is only a

\footnotetext{
${ }^{5}$ Steers and Rhodes (1978) do not fully take into account that ability may influence motivation; the motivation to attend work is, e.g.. likely to decline in the presence of minor illness. In the following, the term "effects of motivation" should therefore be understood as "effects of motivation not due to ability."
} 
matter of motivation and long-term absence only a matter of lack of ability to carry out the work. Very often, both types of absence are likely to be influenced both by motivation and by a more or less serious medical condition. Nevertheless, it seems reasonable to assume that motivation is relatively more important for short-term absence and that illness and injury are relatively more important for long-term absence.

The implicit assumption in discussions of absenteeism is typically that less is better. However, this may not always be the case. If people go to work when ill (i.e., so-called presenteeism), their medical conditions may deteriorate and, in the case of infectious diseases, colleagues or other people may be infected (Johns 2010). The combination of a generally high level of absenteeism and a generally healthy population suggests that the level of presenteeism is relatively low in Norway. ${ }^{6}$ It might nevertheless be argued that at least some of the observed sector difference in absenteeism arises because of too much presenteeism in the private sector (see Section 3.2 below).

\subsection{The private-public sector distinction}

At an idealtypical level, Dahl and Lindblom (1992[1953]) distinguished between private enterprises, whose behavior is mainly determined by the market, and public agencies, which are controlled by political processes (Rainey 2009). Public versus private ownership then becomes an obvious criterion for distinguishing between the sectors. Moreover, ownership may be relevant as an influence on the motivation of the organization's management and employees (François 2000). Other factors than ownership may also have an impact on the relative importance of the market and of political processes, such as the extent to which the organization receives its financial resources from the government or from private customers (Wamsley and Zald 1973), or is the subject of government regulation (Salamon and Elliott

\footnotetext{
${ }^{6}$ In terms of life expectancy, Norway was number 15 on WHO’s 2015 list, while the US was 31 and the UK 20. (http://www.who.int/gho/publications/world_health_statistics/2016/EN_WHS2016_AnnexB.pdf?ua=1).
} 
2002). These factors are difficult to operationalize, however, and in this paper I rely on a pure ownership criterion.

\section{Selection and other factors that may affect public and private sector absenteeism}

\subsection{Weak attendance incentives and negative selection}

The negative selection argument has mainly been elaborated within economic literature. According to much economic reasoning, the combination of no market competition and inefficient political control reduces public organizations' incentives to reduce or contain costs (Dahl and Lindblom 1992[1953]:458ff.; d'Amuri 2017). Less effort to control absenteeism can therefore be expected. The available evidence indicates that public employees indeed tend to have more employment protection than have those employed in the private sector, and often better economic compensation during sickness absence (Kearney and Mareschal 2014; Bossaert 2005). The overall wage dispersion is also smaller in the public sector in many countries, so promotions are less valuable, and there is less reason to have a good absence record (Dale-Olsen and Nilsen 2009; Depalo, Giordano and Papapetrou 2015). With weaker incentives to avoid absenteeism, employees with a high level of absence from work are expected to prefer the public sector (Böhm and Riedel 2013; Delfgaauw and Dur 2008; Dur and Zoutenbier 2015; Pfeifer 2013).

I have only been able to find two studies that have tried to assess the degree to which there is a selection of absence-prone employees to the public sector, both from Germany. Moreover, these studies reach very different conclusions. Böhm and Riedel (2013) concluded that about half of the sector difference in absenteeism was due to negative selection and the other half to direct effects of current sector of employment. Riphahn (2004), on the other hand, found no evidence that people with high absenteeism are more likely to enter the public sector.

\subsection{Prosocial motivation and positive selection}


Although the focus in this paper is on the question of negative selection to the public sector, theory and evidence on other selection processes that potentially may affect sector differences in absenteeism need to be considered. Within public administration research the main theory of selection to the public sector is probably the theory of Public Service Motivation (PSM). Rainey and Steinbauer (1999:20) define PSM as a "general, altruistic motivation to serve the interests of a community of people, a state, a nation or humankind.” Several other definitions have been suggested, but a common theme is a reference to altruism or similar notions such as self-sacrifice or pro-sociality (Perry, Hondeghem and Wise 2010). Although individuals with high levels of PSM are found in both sectors, the opportunities for realizing PSM values are assumed to be better in the public sector. A positive selection to the public sector of people with high PSM motivation is therefore expected (Leisink 2008; Wright, Hassan and Christensen 2017a).

There is cross-sectional evidence of more pro-social value orientations and behaviors among public than private employees (Crewson 1997; Houston 2006; Houston 2011; Lewis and Frank 2002; Piatak 2015; Van de Walle, Stein and Jilke 2015), but little direct evidence on selection to public employment. Studies of students attending specific programs such as law or physiotherapy have yielded mixed results, suggesting that the effect of values on sector choice could be mediated to a greater or lesser extent by educational choices (Choi and Chung 2017; Kjeldsen and Jacobsen 2012; Wright, Hassan and Christensen 2017). In a relatively broad sample of university students, however, Holt (2018) found that pro-social values were associated with later public sector employment.

Using unpaid overtime work as an indicator of pro-social behavior, a study by Gregg et al. (2011) also provides some evidence on selection to the public sector of people with high levels of pro-social motivation. Gregg et al. (2011) found more unpaid overtime work in the public than in the private sector, suggesting more pro-social motivation in the public sector. 
However, sector switchers were not found to do more overtime work when they were in the public sector than they were in the private sector. The lack of a behavioral change among switchers were interpreted as evidence that the overall sector difference was not due to current work or employment conditions, but instead to a selection to the public sector of individuals with a high level of pro-social motivation.

An over-representation of PSM-oriented workers will of course only contribute to a lower level of absenteeism in the public sector if these workers are less absent from work than are other employees. As noted by Wright, Hassan, and Christensen (2017) “public employees with higher PSM may be less likely to be absent from their job because such an absence not only means missing opportunities to perform work that helps others or benefits society, but may come at a cost to the communities they want to serve to the extent that an employee's absence adversely effects service delivery.” Thus, there seem to be good theoretical reasons for expecting PSM to reduce absenteeism. An important precondition, however, is that the absenteeism is to a non-trivial extent a matter of motivation and not completely a result of a lack of ability to attend. I have argued above that this is a reasonable assumption, particularly for short-term absence, and Wright, Hassan and Christensen (2017; see also Wright and Pandey 2011) also cite several pieces of relevant empirical evidence.

However, it has been suggested that PSM may also increase absenteeism. According to Jensen, Andersen, and Holten (2017) PSM may increase presenteeism (and thus reduce absenteeism in the short run), which may have negative long run health consequences and thus lead to an increase in absenteeism. Jensen, Andersen, and Holten (2017) also present some empirical evidence in favor of this idea. Other studies have found that PSM is positively related to work stress (Giauque, Anderfuhren-Biget and Varone 2013) and burnout (van Loon, Vandenabeele, and Leisink 2015), factors that may also increase absenteeism.

To my knowledge, only four studies have attempted to estimate the effect of PSM on 
absenteeism. Three of these find no effect at all (Edwards 2014; Jensen, Andersen, and Holten 2017; Wright, Hassan and Christensen 2017), while one finds that PSM reduces absence frequency but increases the number of absence days (Koumenta 2015). Time lost measures such as the number of absence days are very sensitive to long-term absence, whereas frequency measures primarily reflect short-term absence (Hackett and Guion 1985). Edwards (2014), Jensen, Andersen, and Holten (2017) and Wright, Hassan and Christensen (2017) all use number of absence days (or hours) as their dependent variable, so there is some evidence that PSM does not contribute to less long-term absenteeism. Koumenta's (2015) analysis of absence frequency suggests that there might be an effect on short-term absence, but the generalizability of a single study of a specific population (employees in a prison) is of course small.

\subsection{Both negative and positive selection?}

As noted above, an understanding of absenteeism as strongly influenced by economic incentives implies an expectation of selection of absence-prone individuals to the public sector, whereas PSM theory predicts a selection of employees with relatively high work motivation. Dur and his colleagues (Delfgaauw and Dur 2008; Dur and Zoutenbier 2015) have proposed a model which combines these two perspectives, implying that the public sector attracts both PSM-oriented and what they call "lazy” workers. Individuals may prefer the public sector because of altruistic motivations or because "laziness" is less penalized there than in the private sector. In Delfgaauw and Dur (2008) it is pointed out the term "lazy" implies only that the individual in question incurs a relatively great disutility from work. This could be because of a weak work ethic, but also, for instance, health problems. However, the empirical analysis of Dur and Zoutenbier (2015) is based on a direct survey question that probably mainly measures laziness in the everyday sense of the word.

\subsection{Selection on other personal characteristics}


As noted above, a number of studies have examined the association between sector of employment on the one hand and PSM or related measures of pro-social values on the other. A largely overlapping literature have considered sector differences in other work values. There is some evidence that concern with job security is more common among public employees (Houston 2011) or that it increases the probability of choosing public sector employment (Choi and Chung 2017), but also contrary findings (e.g., Kjeldsen and Jacobsen 2012). A positive association between concerns with job security and public sector employment is in line with other research showing that risk averse individuals are more likely to choose public sector employment (Buurman et al. 2012). No consistent pattern has emerged with regard to other job values such as high income, advancement possibilities or interesting work tasks (for an overview, see Chen, Bozeman and Berman 2018).

For the purposes of this paper, sector differences in work values and motivations are of interest only if they influence absenteeism. I have discussed this above with regard to PSM. I am not aware of any research on the relations between other work values and absenteeism. Risk aversion might have an impact, but it is not clear in what direction. On the one hand, a high level of risk aversion could contribute to better health among public sector employees, as risk aversion should make unhealthy behaviors less likely (Anderson and Mellor 2008). On the other hand, risk averse individuals might be less willing than other individuals to take the risk of going to work when experiencing minor health problems.

As mentioned above, a higher proportion of women and elderly employees are likely to contribute to higher absenteeism in the public than in the private sector (Uppal and LaRochelle-Côté 2013). A higher average level of education among public sector employees (Hugrée, Penissat and Spire 2015) can be expected to work in opposite direction, as higher educated people are in general in better health (Knesebeck, Verde and Dragano 2006). Health may also directly influence selection to the private and public sectors. Private employers 
might be more cost conscious and less inclined to employ people with health problems and potentially high levels of absenteeism. People with health problems may also believe performance and attendance pressures to be weaker in the public sector and therefore choose public sector employment.

\subsection{Alternatives to selection explanations: Direct sector effects}

Above we have discussed how characteristics of the public and the private sector (e.g., the sanctioning of absence from work or the opportunity to realize prosocial values) may be expected to influence the composition of the workforce and thereby also the sector's amount of absenteeism. However, such characteristics may also have direct effects on those already employed in the sector.

There are also structural differences between the sectors. The industrial and occupational composition is clearly different, and there are large occupational differences in absenteeism (Piha et al. 2012). Whether these differences contribute to higher or lower absenteeism in the public compared to the private sector is not clear, however, as there are high and low absenteeism occupations in both sectors. A further difference is size. Public organizations are on average larger, and many studies have found a positive correlation between organizational size and absenteeism (Barmby and Stephan 2000).

\subsection{Hypotheses}

The aim of this study is to assess to whether sector differences in absenteeism are likely to be at least in part the result of a selection of employees to the public sector with relatively low attendance motivation. From this point of departure, three hypotheses can be suggested.

H1: The level of absenteeism is higher in the public than in the private sector even with control for observed individual and organizational characteristics.

Although I am able to control for a number of important variables, there is no guarantee that all important confounders are included. Unobserved health differences are 
perhaps the most obvious problem. This is further addressed by a comparison of short-term and long-term absenteeism. Since health differences are assumed to be relatively more important for long-term absence and attendance motivation for short-term absence, the next hypothesis can be stated as follows:

H2: The excess amount of absenteeism in the public compared to the private sector is larger for short-term than for long-term absences.

Rejection of H2 may be taken as support for a health differences explanation of the higher public sector absenteeism.

H3 tests whether the higher level of absenteeism in the public sector is due to the selection of employees to the sector or to effects of current sector of employment. The selection explanation implies that the sector difference in absenteeism is primarily driven by relatively stable individual characteristics; thus, change of sector should have little effect.

H3: Sector switching is not associated with major changes in absenteeism.

By contrast, the direct sector effects explanation implies that individuals change their behavior when switching from one sector to the other. In order to account for the overall sector difference, the change in connection with the sector switch would also have to be of the same magnitude as this difference.

\section{The institutional context}

All Norwegian employees, in both sectors, are quite well protected against dismissal (Helvik 2017). In particular, it is a general requirement that all dismissals must be justifiable; if this is not the case, the dismissal may be declared invalid in court. However, labor unions are considerably stronger in the public sector (82 percent are unionized in the public sector, 39 in the private; Nergaard and Stokke 2010) and employees risking dismissal may expect to receive more support in the public sector. In addition, lay-offs for economic or business reasons are largely limited to the private sector, and employees with high levels of absence 
from work may be more vulnerable in such lay-off processes. ${ }^{7}$ Wage-setting and promotions are, moreover, based on more standardized criteria in the public sector, so absence from work is likely to be less consequential for the employee than in the private sector.

Norway has a national sickness absence compensation scheme that covers all employees (Dale-Olsen 2014). Absent employees are entitled to full compensation up to a ceiling. In the public and part of the private sector, collective contracts secure full compensation even above the ceiling, and in the private sector individual contracts may also have such provisions. For short absences, certification from a physician is not required; in most of the private sector, certification is necessary beyond three days of absence, otherwise the limit is eight days.

Norway has a large public sector with 32 percent of total employment in 2009, compared to the OECD average of $21 .{ }^{8}$ Unemployment is generally low; in the 2003 to 2012 period it was highest in 2005 (4.4 percent) and lowest in 2007 (2.5 percent). ${ }^{9}$ On average, the standard of living is among the highest in the world, and the wage dispersion is relatively low. ${ }^{10}$

\section{Data}

The Labor Force Survey (LFS) is the Norwegian counterpart of the US Current Population Survey (CPS). It is carried out by Statistics Norway and is a continuous survey of the

\footnotetext{
${ }^{7}$ According to an OECD survey, there was no use of dismissals to reduce the number of employees in the Norwegian public sector in the 2008-2015 period (https://qdd.oecd.org/data/GOV_HRMBUD).

${ }^{8}$ http://www.oecd-ilibrary.org/governance/government-at-a-glance-2015/employment-in-the-publicsector_gov_glance-2015-22-en

${ }^{9}$ https://data.oecd.org/unemp/unemployment-rate.htm\#indicator-chart

10 https://data.oecd.org/gdp/gross-domestic-product-gdp.htm; http://www.oecd-ilibrary.org/social-issuesmigration-health/divided-we-stand/trends-in-wage-dispersion-selected-oecd-countries-1980-

2008_9789264119536-graph29-en
} 
Norwegian population 15 to 74 years of age. Using the National Registry ${ }^{11}$, which contains all present and past residents in Norway, a probability sample of individuals stratified by geographical regions (counties) is drawn and all eligible respondents in these individuals' households are interviewed by telephone. Sampled respondents are interviewed once in each quarter for eight consecutive quarters. Data for the years 2006 to 2012 are used. I exclude people who are self-employed or not employed and individuals younger than 20 or older than 64. In 2006 to 2012, the annual number of observations (interviews) is between 59355 and 67998 with a response rate between 80 and 85 percent. Weights provided by Statistics Norway are employed to correct for stratified sampling and different amounts of non-response in subgroups (Oguz-Alper 2018:10-11). ${ }^{12}$ The survey data are supplemented with administrative data from Statistics Norway and the Norwegian Labor and Welfare Administration. Statistics Norway linked the various sources of data using personal identification numbers and removed these numbers before making the data available for research.

Respondents are asked about their actual hours worked in a given reference week (usually the week before the interview) as well as the number of hours they would ordinarily have been expected to work in this week. Using an open-ended but pre-coded question, those who have worked less than their contracted or usual hours are then asked why. ${ }^{13}$ For all years taken together, 75.0 percent of the cases of complete or partial absence during the week could clearly be categorized as agreed upon in advance (e.g., vacation, planned parental leave) or

\footnotetext{
${ }^{11}$ This registry is maintained by The Norwegian Tax Admininstration, see https://www.skatteetaten.no/en/person/national-registry/om/this-is-the-national-registry/

${ }^{12}$ Results with and without these weights are very similar.

${ }^{13}$ The questionnaire is available at http://ec.europa.eu/eurostat/statisticsexplained/index.php?title=EU_labour_force_survey_-_methodology.
} 
not under the control of the employee (e.g., temporary layoff, strike), 23.1 percent as due to own or a family member’s illness, and 1.9 percent was either ambiguous (e.g., "bad weather”), classified as “other causes”, or missing. Nearly all unscheduled absences thus fall in the own and family illness category. Cases of outright shirking will presumably largely be included here, too, since no documentation of actual illness is necessary to receive compensation for short spells reported as due to sickness. A few cases of shirking are nevertheless likely to fall in the "other" or missing categories, but the number of such cases must necessarily be very low. Only those reporting work attendance or absence due to own or family illness are included in the analysis sample; in the following the term total absence therefore refer to the total amount reported as due to these causes.

Using these interview data, short-term absence is measured as the proportion of the reference week that an employee was absent:

short-term absence $=\frac{\text { scheduled working hours-actual working hours }}{\text { scheduled working hours }}$

To contrast short-term absence to no absence in the analyses, employees who were absent the whole week were coded as missing. Long-term absence is measured in a similar way, but with the use of administrative data, and on a quarterly instead of weekly basis (the proportion of the working days in the quarter that are lost due to absence). ${ }^{14}$ This information is taken from a register covering all physician-certified absence in Norway. ${ }^{15}$ The physician reports starting and termination dates for the absence period; potential later changes of the termination date (if periods are extended or terminated earlier than stated at the outset) are also reported. Absence spells of less than nine days' duration do not always require certification from a physician

\footnotetext{
14 The administrative data are used because a period of observation of a quarter instead of a week provides considerably more reliable data.

${ }^{15}$ Physicians are required by law to report all sickness certifications to the Norwegian Labor and Welfare Administration.
} 
(and will therefore not always be included in the register). Long-term absence is therefore defined as the proportion of scheduled days during the quarter that the employee was absent in an absence spell of at least nine days' duration. Since they are proportions, both absence measures have a range of zero to one (although never exactly one for short-term absence, since absence during the entire reference weak is by definition not included).

The main explanatory variable is sector of employment. This is based on a national register of employers that provides information on ownership. The public sector includes state and local government as well as establishments that are fully owned by the government (such as most hospitals and the public broadcasting organization). Remaining employers are classified as private sector, apart from non-profit organizations, a very small sector in Norway, which are not included in the analyses. ${ }^{16}$

Control variables: Age is measured in units of 10 years (which is preferable to oneyear units to avoid an excessive number of zeros in the tables). Gender is coded 0 for men and 1 for women. Level of education: dummy variables for some upper secondary, full upper secondary, post-secondary but less than bachelor level, bachelor level, master level, and PhD level, with lower secondary or less as reference. Children: Nine dummy variables that take into account both the number of children below 17 (1, 2, and 3 or more children) and the age of the youngest child (2 to 5, 6 to 10 and 11-16 years), with no children as reference. Women with children of one year or younger are not included in the analyses since they are typically on parental leave. Information on the number of children and age of youngest child is available only for women. ${ }^{17}$ Occupation: Detailed, four-digit codes in the Norwegian version

\footnotetext{
${ }^{16}$ See http://www.ssb.no/klass/klassifikasjoner/39/versjon/93. The public sector encompasses codes 110-190, 510, 550, and 610-680 and the private sector codes 210-497 and 710-717. Codes 760-900 are excluded.

${ }^{17}$ In the regressions, the variable is coded as zero for men, thus constraining the effect of children to be zero for them.
} 
of the International Standard Classification of Occupations (ISCO) from the International Labor Organization (ILO). ${ }^{18}$ Size (number of employees): Dummies for 1-10 , 11-19, 20-49, 50-99, 100-199, and 200 or more, plus a separate dummy for more than 10, if more exact information is not available. Degree of urbanization of the local area in which the respondent lives is measured by a Norwegian standard classification of municipalities that also take into whether the dominant industries are services, manufacturing or agriculture or fisheries. Seven dummy variables are included with the most urbanized as reference.

The Labor Force Survey is the Government's main instrument for regular monitoring of the labor market, and a high quality of data is therefore to be expected. I am not aware of specific information on the reliability or validity of the data on absence from work, but the measurement procedures are very similar in the labor force surveys in most European countries and in the American CPS. ${ }^{19}$ Since respondents are asked about absence from work in the past week, memory problems should be minimal. The administrative data on physiciancertified absence is the basis for the payment of each absentee's absence compensation, and should therefore be highly reliable.

\section{Statistical methods}

Since the absenteeism measures have a lower bound of zero, ordinary linear regression (OLS) is not ideal, and I use Poisson regression with an exponential link function (see, e.g.,

\footnotetext{
${ }^{18}$ The coding scheme was changed in 2011 (from being based on ISCO-88 to ISCO-08). I therefore include interaction terms of each category with a dummy distinguishing between the years 2003-2010 and 2011. The number of different occupational categories in the data is 334 in 2003-2010 and 373 in 2011.

${ }^{19}$ With regard to the CPS, see https://www2.census.gov/programssurveys/cps/techdocs/questionnaires/Labor\%20Force.pdf. For Europe, see http://ec.europa.eu/eurostat/statisticsexplained/index.php?title=EU_labour_force_survey_-_methodology.
} 
Wooldridge 2010: Ch. 18). ${ }^{20}$ For present purposes, this method also has the advantage of providing coefficients that when exponentiated can be directly interpreted as relative or percentagewise effects, which makes it easier to compare the results for short-term and longterm absenteeism. I start by regressing each absenteeism measure (ABS) on a dummy variable for the public sector (PUB), with various sets of control variables:

$E\left(A B S_{i}\right)=\exp \left(\alpha+\beta P U B_{i}+\gamma \boldsymbol{X}_{\boldsymbol{i}}\right)$

$E\left(A B S_{i}\right)$ is the expected level of absenteeism for individual $i, \boldsymbol{X}_{\boldsymbol{i}}$ is a vector of control variables, $\alpha$ is the intercept, $\beta$ is the coefficient for the sector dummy, and $\gamma$ is a vector of coefficients for the control variables.

In order to address the question of selection to the public sector (either favorable or unfavorable), a longitudinal analysis of how absence from work develops in the years before and after the sector switch would have been desirable. Unfortunately, the present data are not suited for such an analysis. In the first place, the individuals are followed only over two years, and the level of absence shortly before and after a switch may be highly untypical, for instance due to probation periods. Even more importantly, the standard errors would be so high that no conclusion could be drawn. However, I do have information on each individual's sector of employment for the whole period 2003 to 2012 since this is taken from administrative records. This means that we know for each public (private) sector employee interviewed whether he or she has previously been in the private (public) sector, or will move to the private (public) sector in the years following the interview. This longitudinal information makes is possible to distinguish between non-switchers, who are in one sector

\footnotetext{
${ }^{20}$ Poisson regression was originally developed for count variables with Poisson distributions. However, this assumption is not necessary to obtain consistent estimates of the coefficients. Ordinary (model based) estimates of the standard errors are biased, but this problem is solved by using robust standard errors. See Wooldridge (2010: Ch. 18).
} 
only in the years 2003 to 2012, and switchers, who are in both sectors during this period. The assumption is that for people who switch sectors it is largely random (or at least not strongly influenced by stable personal characteristics) whether they happen to be in the public or the private sector in a particular year. Thus, a comparison of private and public switchers should reveal the direct effects of current employment in the public versus the private sector net of selection effects (cf. Gregg et al. 2011). The difference in absenteeism between public and private non-switchers, on the other hand, should reflect both the direct effects of current sector of employment and predispositional differences between those who are selected to the two sectors. ${ }^{21}$

To compare switchers and non-switchers, he following regression model is estimated:

$$
E\left(A B S_{i}\right)=\exp \left(\alpha+\beta P U B_{i}+\lambda N S_{i}+v P U B_{i} \cdot N S_{i}+\gamma \boldsymbol{X}_{\boldsymbol{i}}\right)
$$

$P U B_{i}$ is a public sector dummy, $N S_{i}$ is a dummy variable for non-switchers, $P U B_{i} \cdot N S_{i}$ is the interaction of these variables, and $\boldsymbol{X}_{\boldsymbol{i}}$ is a vector of control variables. $\alpha$ is the intercept, $\beta, \lambda$ and $v$ are coefficients, and $\gamma$ is a vector of coefficients. Because of the interaction term, $\beta$ is now the difference between the public and the private sector among switchers only, and $\lambda$ is the difference between non-switchers and switchers among private sector employees. $\beta+v$ is the difference between the public and the private sectors among non-switchers. For present purposes, therefore, the crucial comparison is between $\lambda$ on the one hand and $\beta+v$ on the other.

[Table 1, Figure 1]

\section{Results}

\subsection{Descriptives}

\footnotetext{
${ }^{21}$ It would have been desirable to take into account the direction of the switches, but the total number of switches in the data is not sufficient to obtain acceptable estimates of the separate effects of private to public and public to private switches.
} 
Descriptive statistics for the absenteeism measures and for the most important explanatory variables are given in Table 1. (For the sake of brevity, information on the distributions of the remaining variables is in an Online Appendix.) In the public sector, the proportion of the reference week lost to absence is, on average, .015 (or 1.5 percent), as compared to .012 in the private sector. In terms of hours lost during a 37.5 hours working week, this corresponds to an average of .56 $(.015 \cdot 37.5)$ hours in the public sector and .45 hours in the private sector. The low numbers reflect that only a very small proportion of the employees have any short-term absence at all in any given week, more specifically 4.3 percent in the public and 3.5 percent in the private sector (Table 1).

The average time loss due to long-term absence is .053 of the quarter in the public and .042 in the private sector. Assuming 65 workdays in the quarter, this corresponds to an average loss of 3.45 workdays $(.053 \cdot 65)$ in the public and 2.73 workdays in the private sector. The table also shows that the percentage with at least some long-term absence in the quarter is 14.2 in the public and 11.0 in the private sector.

The proportion of women is almost twice as large in the public as in the private sector. The level of schooling is also markedly higher, while the average age is only moderately higher. Technicians and Services and Sales Workers are the largest categories in both sectors; beyond this, professionals are the largest category in the public sector, whereas Craft Workers, etc. and Plant and Machine Operators, etc. are the largest ones in the private sector. $^{22}$

[Tables 2 and 3]

\subsection{Overall sector differences}

Table 2 shows results from regression analyses of short-term absence. Without control variables (Model 1), the estimated sector difference in exponentiated form is 1.26 . The

\footnotetext{
${ }^{22}$ Detailed, four-digit codes are used in the regressions.
} 
interpretation is that the ratio of public to private time loss is 1.26 , or that the level of absence of public sector employees is 26 percent higher than that of private sector employees. Model 2 controls for the socio-demographic composition of the labor force in the sectors, that is, for gender, children, age, and level of education, along with degree of urbanization. Women’s absence is higher than men's, and the level of short-term absence is particularly high when the women have small children. Short-term absenteeism declines as a function of the level of education. Due to the higher order terms, the impact of age is not seen directly in the table. If the coefficients are used to compute predicted values, it turns out that absenteeism is low among the youngest, but increases and reaches its maximum when the employees are in their early thirties. After that, short-term absenteeism declines until it levels off when the employees are about sixty years of age. Inclusion of these control variables leaves the estimated sector difference almost unchanged. Additional analyses (not shown) indicate that the gender composition of the sectors tends to increase the difference between the public and the private sector (women are more absent and there are more women in the public sector), whereas age and the level of education have some impact in the opposite direction (the mean age and the mean level of education are higher in the public sector and high values on both these variables contribute to lower short-term absence).

Model 3 controls for the occupational composition of the sectors and for organizational size. The number of employees is weakly and non-monotonically related to short-term absenteeism, and additional analyses (not presented) show that this control has minimal impact on the estimated sector difference. Control for detailed occupation has also very little impact. Model 4 includes all control variables simultaneously. If anything, there is now a small increase in the coefficient for sector. Overall, it is clear that neither the socioeconomic variables nor organizational size or the occupational composition of the two sectors contribute to explaining the sector difference in short-term absenteeism. 
Results for long-term absence are shown in Table 3. Consistent with Table 1, Model 1 shows that the ratio of public to private sector absenteeism is 1.26 . Model 2 shows that women are much more absent than men; the relative gender difference is three times as large as for short-term absenteeism (Table 2). Absenteeism also increases strongly with age; computation of predicted values shows that it is nearly three times higher when people are 6064 years of age as when they are 20 to 24 . There is a strong negative relationship between level of education and absenteeism, which declines to less than a third when comparing the graduate (master) level with those with compulsory education only. The total impact of the socio-demographic variables is a reduction of the estimated sector difference from 1.25 to 1.15. Additional analyses in which the control variables are included one at a time shows that control for gender and age both reduces the estimated sector difference considerably, while control for education has the opposite effect. The impact of controlling for detailed occupation and organizational size is even larger and reduces the estimated sector difference by about two thirds (Model 3 compared to Model 1). Additional analyses (not shown) indicate that this is wholly a result of the control for occupation; control for the number of employees has negligible impact. With all the control variables included simultaneously, the coefficient for sector is for all purposes identical to zero.

To sum up, age and gender contribute quite strongly to higher public sector long-term absenteeism. Public sector employees are also strongly overrepresented in occupations with a high level of long-term absence. On the other hand, control for level of education increases the estimated sector difference; in other words, a relatively high level of education in the public sector helps to keep the level of long-term absence in the sector down. As far as shortterm absence is concerned, inclusion of the control variables has little impact.

As for the hypotheses, $\mathrm{H} 1$ stated that the level of absenteeism would be higher in the public than in the private sector even with control for individual and institutional 
characteristics. The results for short-term absence support this hypothesis (Model 4 in Table 2), but there is no sector difference in long-term absence when these control variables are included (Table 3). The very different results for short-term are long-term absenteeism are striking, and there is strong support for the hypothesis of greater sector differences for shortterm than for long-term absence (H2).

\section{[Table 4, Figure 1]}

\subsection{Sector switchers and non-switchers}

H3 states that sector switching should not be associated with major changes in the level of absenteeism. I test it by comparing the public - private difference in absenteeism among stayers to that among switchers, i.e., Equation (3) is estimated. All control variables are included, but for brevity only the most important coefficients are presented in Table 4 (full results in Table A4 in the Online Appendix).

Because of the inclusion of the interaction term, the coefficient for the public sector gives the estimated sector difference for the switchers. Since these are people who move between the sectors, the fact that they are in the public sector at a specific point in time is unlikely to be an effect of stable predispositions. Within the switcher group, therefore, public and private sector employees should not differ due to selection and the estimated difference should reflect the pure effect of current sector of employment. The sum of the coefficient for public sector and the interaction term gives the sector difference for stayers. Since we now compare workers who are stably employed in the public sector with those who are stably employed in the private sector, this difference is the sum of the effects of current employment in the public sector and sector differences that are due to selection.

Figure 1 shows the relative sector differences for both switchers and non-switchers for each absenteeism measure, as calculated from the coefficients in Table 4. To facilitate the interpretation, the relative differences are given in terms of percentages. As far as short-term 
absenteeism is concerned, Figure 1 shows that the estimated difference between switchers currently in the public and in the private sector is only 10 percent, which is not significantly different from zero. Among non-switchers on the other hand, the corresponding estimate is 34 percent. Since the estimated difference among switchers is assumed to be mainly due to direct sector effects whereas the difference among non-switchers reflects both direct sector effects and selection to the sectors, the results suggest that the sector difference in short-term absence is mainly a result of selection.

With regard to long-term absenteeism, the switchers currently employed in the public sector have 19 percent lower absence than have switchers in the private sector. Among nonswitchers the level of absence is higher in the public than in the private sector, but the difference is small (13 percent). These results suggest that employment in the public sector has a favorable direct effect on long-term absenteeism, but it is counterbalanced by an unfavorable selection effect.

Assuming that the sector differences in absenteeism were entirely due to selection and not to sector effects, H3 implies a sector difference only among non-switchers. The results for short-term absence are in line with this hypothesis. With regard to long-term absence, however, there is a significant sector difference even among switchers. Thus, a switch from the private to the public sector seems to be associated with a drop in long-term absence (and a switch in the opposite direction with an increase). Taken together, the comparison of switchers and non-switchers suggests that the higher level of absenteeism in the public sector is entirely driven by selection. To the extent that there is an effect of current employment sector (as there is for long-term absences), it is less than one, suggesting that public sector employment contributes to lower absenteeism.

\section{Discussion}

The analyses have shown that the sector differences are very dissimilar for long-term and 
short-term absenteeism. All of the three hypotheses were supported for short-term absenteeism, whereas both H1 and H3 were rejected for long-term absenteeism.

The sector difference in short-term absenteeism is very little affected by control for socio-demographic characteristics and the occupational composition of the sectors. This is in line with H1. The fact that these control variables are much more important for long-term than for short-term absenteeism supports H2. In the comparison of switchers and non-switchers, there is only a small and non-significant sector difference within the group of switchers but a considerably larger and significant sector difference among non-switchers. This supports H3. The finding that switchers have the same level of absenteeism in the private and in the public sector indicates that the overall sector difference is not a result of the current sector of employment, but instead a result of selection on stable individual characteristics.

Overall, the results for short-term absenteeism are in line with the idea that the sector difference in this kind of absenteeism is driven by selection to the public sector of employees with a relatively high probability of absence from work. The analysis of short-term absenteeism cannot in itself say whether the relatively high absence probability is due to motivation or ability factors. The fact that the selection effect appears to be considerably weaker for long-term absenteeism suggests, however, that motivational factors are likely to be important.

With regard to long-term absenteeism, H1 is rejected. There is no difference in longterm absenteeism once we compare people in the two sectors who have identical sociodemographic characteristics and the same detailed occupation. The further analyses of switchers and non-switchers suggest that this lack of a sector difference when controlling for covariates is the net result of two opposing processes. On the one hand, switchers currently in the public sector have lower absenteeism than switchers currently in the private sector. Thus, current employment in the public sector seems to contribute to less long-term absenteeism, 
and H3, assuming no effect beyond selection, can be rejected. On the other hand, public sector non-switchers have a slightly higher level of long-term absenteeism than have private sector non-switchers. Thus, there seems to be some selection of people prone to high long-term absenteeism to the public sector.

As argued above, there is no reason to believe that short-term absenteeism is only a matter of motivation and long-term absenteeism only of the ability to attend work. Thus, the weak selection effect found in the analyses of long-term absenteeism might be primarily due to motivational factors. However, an explanation in terms of health-based selection seems easier to reconcile with the finding that the selection effect comes together with a favorable direct effect on long-term absenteeism of current employment in the public sector. Health selection implies that people with health problems or limitations tend to choose the public sector because they believe the working or employment conditions there are better suited for them (or that public sector employers are more willing to employ people with health problems). If this interpretation is correct, it is also as it should be that the direct effect of switching to the public sector is a reduction of long-term absenteeism. On the other hand, if people choose the public sector because absenteeism is less consequential there, it is harder to explain why switchers should be less absent from work in that sector.

My results on the overall selection versus direct sector effects issue diverge from two German studies of sector differences in the total number of absence days, and in particular Riphahn (2004). Her findings indicated that the sector difference in absenteeism was mainly due to a direct effect of the enhanced employment protection that public employees obtain after 15 years of tenure, and there was no evidence of a selection effect. Böhm and Riedel (2013) concluded that about half of the sector difference in absenteeism was due to effects of current employment sector and the other half to selection. My analyses of long-term absence 
(which accounts for more than 80 percent of total absence) ${ }^{23}$ suggest that the higher level in the public sector is largely due to the socio-demographic and occupational composition of the sectors and that current employment in the public sector contributes to reduced public sector (total and long-term) absenteeism. The different results may reflect true national differences between Germany and Norway, but there are also methodological differences. A limitation of my study is that I can only estimate the effects of sector change for the subpopulation of individuals who actually change sector (i.e., switchers). Riphahn's (2004) findings, on the other hand, are based on a subpopulation of non-switchers, viz. those who have obtained 15 years of tenure in the public sector and who are therefore granted increased employment protection.

The findings in this paper contrast with those of Gregg et al. (2011). They found that employees reported more unpaid overtime work in the public than in the private sector, but that employees did not change their behavior when switching from one sector to the other. Based on similar reasoning as in this paper, they interpreted their results as supporting a hypothesis of positive selection of employees with high pro-social motivation to the public sector. It is difficult to see why differential selection to the public sector should lead to provision of more labor than what is paid for (i.e., unpaid overtime work) in one case and to less labor than is paid for (i.e., absenteeism) in the other, although national differences is always a possibility. More research is clearly needed to settle this issue.

Neither my study nor that of Gregg et al. (2011) or other studies of sector differences in pro-social behaviors (Houston 2006; Piatak 2015) provide direct evidence on behavioral effects of PSM. As far as absenteeism is concerned, three of four previous studies have failed to find an effect or (or association with) PSM (Edwards 2014; Jensen, Andersen, and Holten 2017; Wright, Hassan, and Christensen 2017). Nevertheless, my findings are not incompatible

\footnotetext{
${ }^{23}$ According to Statistics Norway, https://www.ssb.no/en/arbeid-og-lonn/statistikker/sykefratot
} 
with the existence of a favorable effect of PSM on absenteeism. The model presented by Dur and his collaborators (Delfgaauw and Dur 2008; Dur and Zoutenbier 2015) is one way of reconciling such an effect of PSM with high public sector absenteeism. As noted above, these authors suggest that the public sector attracts both those with pro-social motives, and those who prefer to put relatively little effort into their jobs. In terms of this model, the crucial factors are both how strong each of these selection processes are and how strong effects the pro-social motives have on the behavioral outcome under study. A favorable effect of PSM on absenteeism at the individual level might be outweighed either by a stronger effect of laziness on absenteeism or by a greater over-representation of lazy than of pro-socially motivated employees in the public sector (or both).

Norway is a small country, and it also stands out to some extent on several dimensions, such as low unemployment, high average income and a relatively egalitarian income distribution, a large public sector, and generous compensation when absent from work. With regard to public-private sector differences in absenteeism, Norway is, however, similar to other countries. Although statistics from different countries may not be strictly comparable, it may be noted that the gross difference is smaller than that found in Canada, Denmark and the UK, at about the same level as in the Netherlands, and somewhat larger than in Germany (see references in the Introduction). From a theoretical point of view, there seems to be no obvious reason to expect pro-social motivation to be less relevant in Norway than in other countries. With regard to economic incentives for people with low attendance motivation to choose the public sector, a case might be made for expecting these to weaker in Norway than in many other countries. This is so because the degree of employment protection is quite good even in the private sector.

\section{Conclusion}

Public sector employees have considerably higher levels of both short-term and long-term 
absenteeism. The sector difference is also of very similar magnitude for both types of absenteeism. However, the underlying mechanisms seem to be quite different. The results above indicate that the sector difference in short-term absenteeism is likely to be to a considerable extent a result of selection to the public sector of individuals with relatively low attendance motivation. This is consistent with economic models which see sector choice as a function of different incentive structures in the two sectors (d'Amuri 2017; Delfgaauw and Dur 2008; Dur and Zoutenbier 2015; Pfeifer 2013). It should be underscored, however, that the evidence presented here is indirect only and rests on the assumption that motivational factors are relatively more important for short-term than for long-term absence.

The sector difference in long-term absenteeism appears to be more complex. In contrast to the findings for short-term absenteeism, both the socio-demographic composition of the labor force in the two sectors and sector differences in occupational composition seem to play an important role. Selection effects beyond those accounted for by gender, age and level of education are small, and could be primarily health-related rather than motivationrelated. Beyond these compositional and selection effects, public sector employment seems to have a favorable although not large effect on long-term absenteeism, since sector switchers are less absent when employed in the public and not in the private sector.

This study has not provided any evidence on whether PSM-oriented employees are less absent from work than are other workers. The over-representation of PSM-oriented employees in the public sector is not, however, sufficient to avoid considerably higher shortterm absenteeism in the sector. While the public sector may be attractive to workers with prosocial motivations, it seems to be at least equally attractive to individuals with characteristics that contribute to a relatively low attendance motivation (cf. Delfgaauw and Dur 2008). A more precise identification of these characteristics, however, must await further research. 


\section{Funding}

This work was supported by the Research Council of Norway [grant numbers 187928, 202647, 227117].

\section{Acknowledgements}

Data were made available by Statistics Norway. The author has full responsibility for analyses and interpretations. I am grateful to Hege Torp for helpful comments on the paper. 


\section{References}

Anderson, Lisa R., and Jennifer M. Mellor. 2008. Predicting health behaviors with an experimental measure of risk preference. Journal of Health Economics 27:1260-1274

Anghel, Brindusa, Sara de la Rica, and Juan J. Dolado. 2011. The effect of public sector employment on women’s labour market outcomes. IZA Discussion Paper No. 5825. Bonn: Institute for the Study of Labor.

Barmby, Tim, and Gesine Stephan. 2000. Worker absenteeism: why firm size may matter. The Manchester School 68:568-577.

Böhm, Tobias, and Nadine Riedel 2013. On selection into public civil service. CESifo Economic Studies 59:34-71.

Bossaert, Danielle. 2005. The flexibilisation of the employment status of civil servants: From life tenure to more flexible employment relations? Luxembourg: European Institute of Public Administration.

Brown, Sarah, and John G. Sessions. 1996. The economics of absence: Theory and evidence. Journal of Economic Surveys 108:23-53.

Buurman, Margaretha, Josse Delfgaauw, Robert Dur, and Seth Van den Bossche. 2012. Public sector employees: Risk averse and altruistic? Journal of Economic Behavior and Organization 83:279-291.

Chen, Chung-An, Barry Bozeman, and Evan Berman. 2018. The grass is greener, but why? Evidence of employees’ perceived sector mismatch from the US, New Zealand, and Taiwan. International Public Management Journal DOI: $10.1080 / 10967494.2018 .1425228$

Choi, Yujin, and Il Hwan Chung. 2017. Attraction-selection and socialization of work values: Evidence from longitudinal survey. Public Personnel Management 46:66-88.

Conti, Gabriella, James Heckman, and Sergio Urzua. 2010. The Education-Health Gradient. 
American Economic Review: Papers \& Proceedings 100: 234-238.

Coursey, David H., and Sanjay K. Pandey. 2007. Content domain, measurement, and validity of the red tape concept: A second-order confirmatory factor analysis. American Review of Public Administration 37:342-361.

Crewson, Philip E. 1997. Public-service motivation: Building empirical evidence of incidence and effect. Journal of Public Administration Research and Theory 7:499-518.

D’Amuri, Francesco. 2017. Monitoring and disincentives in containing paid sick leave. Labour Economics 49:74-83.

Dahl, Robert A., and Charles E. Lindblom. 1992 [1953]. Politics, economics and welfare. New Brunswick: Transaction Publishers.

Dale-Olsen, Harald, and Kjersti Misje Nilsen. 2009. Lønnsulikhet i Norge 1995-2006. Søkelys på arbeidslivet 26:207-221.

Dale-Olsen, Harald. 2014. Sickness absence, sick leave pay, and pay schemes. Labour 28:4063.

Delfgaauw, Josse, and Robert Dur. 2008. Incentives and workers' motivation in the public sector. Economic Journal 118:171-191.

Depalo, Domenico, Raffaela Giordano, and Evangelia Papapetrou. 2015. Public-private wage differentials in euro-area countries: Evidence from quantile decomposition analysis. Empirical Economics 49:985-1015.

Dur, Robert, and Robin Zoutenbier. 2015. Intrinsic motivations of public sector employees: Evidence for Germany. German Economic Review 16:343-366.

Edwards, Vickie L. 2014. Examining absenteeism in the public and non-profit sectors. International Journal of Organization Theory \& Behavior 17:293-310.

Eurofound. 2012. Employment trends and policies for older workers in the recession. Report. European Foundation for the Improvement of Living and Working Conditions. 
Ferrie, J. E., et al. 2009. Diagnosis-specific sickness absence and all-cause mortality in the GAZEL study. Journal of Epidemiology and Community Health 63:50-55.

François, Patrick. 2000. Public service motivation as an argument for government provision. Journal of Public Economics 78:275-299.

Giauque, David, Simon Anderfuhren-Biget, and Frédéric Varone. 2013. Stress Perception in public organisations: expanding the job demands-job resources model by including public service motivation. Review of Public Personnel Administration 33:58-83.

Grandey, Alicia A., and Robert C. Melloy. 2017. The state of the heart: Emotional labor as emotion regulation reviewed and revised. Journal of Occupational Health Psychology 22:407-422.

Gregg, Paul, Paul A. Grout, Anna Ratcliffe, Sarah Smith and Frank Windmeijer. 2011. How important is pro-social behavior in the delivery of public services? Journal of Public Economics 95:758-766.

Hackett, Rick D., and Robert M. Guion. 1985. A reevaluation of the absenteeism-job satisfaction relationship. Organizational Behavior and Human Decision Processes 35:340-381.

Heckman, James J, and Richard Robb. 1985. Alternative methods for evaluating the impact of interventions. Journal of Econometrics 30:239-267.

Helvik, Gro Forsdal. 2017. Norway. In The Employment Law Review, Eighth Edition, ed. Erika C. Collins, 478-489. London: Law Business Research.

Holt, Stephen B. 2018. For those who care: The effect of public service motivation on sector selection. Public Administration Review DOI: 10.1111/puar.12906.

Houston, David J. 2006. "Walking the walk” of public service motivation: Public employees and charitable gifts of time, blood, and money. JPART 16:67-86.

Houston, David J. 2011. Implications of occupational locus and focus for public service 
motivation: Attitudes toward work motives across nations. Public Administration Review 71:761-771.

Hugrée, Cédric, Étienne Penissat, and Alexis Spire. 2015. The distinctive features of public sector in europe: A comparative study based on the social morphology of wage earners. Comparative Sociology 14:252-273.

Jensen, Ulrich Thy, Lotte Bøgh Andersen, and Ann-Louise Holten. 2017. Explaining a dark side: public service motivation, presenteeism, and absenteeism. Review of Public Personnel Administration DOI: 10.1177/0734371X17744865.

Johns, Gary. 2010. Presenteeism in the workplace: A review and research agenda. Journal of Organizational Behavior 31:519-542

Kearney, Richard C., and Patrice M. Mareschal. 2014. Labor Relations in the Public Sector, Fifth Edition. London: CRC Press.

Kjeldsen, Anne Mette, and Christian Bøtcher Jacobsen. 2012. Public service motivation and employment sector: attraction or socialization? JPART 23:899-926.

Knesebeck, Olaf von dem, Pablo E. Verde, and Nico Dragano. 2006. Education and health in 22 European countries. Social Science \& Medicine 63:1344-1351.

Koumenta, Maria. 2015. Public service motivation and organizational citizenship. Public Money \& Management 35:341-348.

Leisink, Peter, and Bram Steijn. 2008. Recruitment, attraction and selection. In Motivation in public management: The call of public service, ed. James L. Perry and Annie Hondeghem, 118-35. New York: Oxford University Press.

Lewis, Gregory, and Sue A. Frank. 2002. Who wants to work for the government? Public Administration Review 62:395-404.

Nergaard, Kristine, and Torgeir Aarvaag Stokke. 2010. Arbeidslivets organisasjoner 2008/2009. Organisasjonsgrader, tariffavtaledekning og tillitsverv. Report 2010:47. 
Oslo: FAFO.

Oguz-Alper, Melike. 2018. New estimation methodology for the Norwegian Labour Force Survey. Documents 2018/16. Oslo: Statistics Norway.

Oksuzyan, Anna, Knud Juel, James W. Vaupel, and Kaare Christensen. 2008. Men: good health and high mortality. Sex differences in health and aging. Aging Clinical and Experimental Research 20:91-102.

Perry, James L., and Lois Recascino Wise. 1990. The motivational bases of public service. Public Administration Review 50:367-373.

Perry, James L., Annie Hondeghem, and Lois Recascino Wise. 2010. Revisiting the motivational bases of public service: twenty years of research and an agenda for the future. Public Administration Review 70:681-690.

Pfeifer, Christian. 2013. Cyclical absenteeism among private sector, public sector and selfemployed workers. Health Economics 22:366-370.

Piatak, Jaclyn Schede. 2015. Altruism by job sector: Can public sector employees lead the way in rebuilding social capital? JPART 25:877-900.

Piha, Kustaa, Mikko Laaksonen, Pekka Martikainen, Ossi Rahkonen, and Eero Lahelma. 2012. Socio-economic and occupational determinants of work injury absence. European Journal of Public Health 23:693-698

Polidori, Paolo, and Désirée Teobaldelli. 2013. Prosocial behavior in the production of publicly provided goods and services: An overview. International Review of Applied Economics 27:285-296.

Rainey, Hal G. 2009. Understanding and managing public organizations. Fourth edition. San Francisco: Jossey-Bass.

Rainey, Hal G., and Paula Steinbauer. 1999. Galloping elephants: Developing elements of a teory of effective government organizations. Journal of Public Administration 
Research and Teory 9:1-32.

Riphahn, Regina T. 2004. Employment protection and effort among German employees. Economics Letters 85:353-357.

Salamon, Lester M., and Odus V. Elliott. 2002 (Eds.). Tools of government: A guide to the new governance. Oxford, UK: Oxford University Press.

Sloan, Melissa M. 2014. The consequences of emotional labor for public sector workers and the mitigating role of self-efficacy. American Review of Public Administration $44: 274-290$

Steers, Richard M., and Susan R. Rhodes. 1978. Major influences on employee attendance: A process model. Journal of Applied Psychology 63:391-407.

Uppal, Sharanjit, and Sébastien LaRochelle-Côté. 2013. Understanding public-private sector differences in work absences. Insights on Canadian Society. Ottawa: Statistics Canada, Catalogue no. 75-006-X.

Vahtera, J., J. Pentti, and M. Kivimäki. 2004. Sickness absence as a predictor of mortality among male and female employees. Journal of Epidemiology and Community Health 58:321-326.

Van de Walle, Steven. 2004. Context-specific images of the archetypical bureaucrat: persistence and diffusion of the bureaucracy stereotype. Public Voices 7:3-12. Van de Walle, Steven, Bram Steijn and Sebastian Jilke. 2015. Extrinsic motivation, PSM and labour market characteristics: a multilevel model of public sector employment preference in 26 countries. International Review of Administrative Sciences 81:833-855. van Loon, Nina Mari, Wouter Vandenabeele, and Peter Leisink. 2015. On the bright and dark side of public service motivation: The relationship between PSM and employee wellbeing. Public Money \& Management 35:349-356.

Wamsley, Gary L., and Mayer N. Zald. 1973. The political economy of public organizations. 
Lexington, MA: Lexington Books.

Wooldridge, Jeffrey. 2010. Econometric analysis of cross section and panel data. 2nd edition. Cambridge, MA: MIT Press

Wright, Bradley E., and Sanjay K. Pandey. 2011. Public organizations and mission valence: When does mission matter? Administration \& Society 43:22-44.

Wright, Bradley E., Shahidul Hassan, and Robert K. Christensen. 2017. Job choice and performance: Revisiting core assumptions about public service motivation. International Public Management Journal 20:108-131. 
Table 1. Descriptive statistics for selected variables

Short-term absence

Proportion lost of working hours in reference week, mean

Private Public

Percent with non-zero absence in reference week

$0.012 \quad 0.015$

Long-term absence

Proportion lost of days in quarter, mean

0.042

0.053

Percent with non-zero absence in quarter

$11.0 \quad 14.2$

Age (10-year units), mean

$4.1 \quad 4.5$

Gender (1=woman), mean

0.340

0.647

Level of schooling (percent)

Lower secondary or less

20.2

11.3

Some upper secondary

11.6

10.9

Full upper secondary

38.6

23.2

Some post-secondary

4.7

2.6

Bachelor level

18.7

40.3

Master level

$\mathrm{PhD}$ level

Occupation, first digit ${ }^{\mathrm{a}}$ (percent)

Managers

$8.6 \quad 5.8$

Professionals

$9.1 \quad 25.2$

Technicians, etc.

Clerical Support Workers

$9.3 \quad 5.9$

Services and Sales Workers

$18.5 \quad 25.6$

Skilled Agricultural Workers, etc.

$0.7 \quad 0.1$

Craft workers, etc.

$17.4 \quad 2.8$

Plant and Machine Operators, etc.

$11.2 \quad 2.3$

Elementary Occupations

Note: For statistics for the remaining variables, see Table A1 in the online appendix. ${ }^{\text {a }}$ Four-digit categories are used in the analyses. 
Table 2. Poisson regression of short-term absence on sector of employment and different sets of control variables. Exponentiated coefficients and their standard errors.

\begin{tabular}{|c|c|c|c|c|c|c|c|c|}
\hline & Model & & Model & & Model & & Model & \\
\hline & $\mathrm{b}$ & se & $\mathrm{b}$ & se & $\mathrm{b}$ & se & $\mathrm{b}$ & se \\
\hline Public sector & $1.258 * * *$ & 0.032 & $1.266 * * *$ & 0.036 & $1.244 * * *$ & 0.051 & $1.293 * * *$ & 0.053 \\
\hline Woman & & & $1.186 * * *$ & 0.041 & & & $1.207 * * *$ & 0.047 \\
\hline Age (10-year units) & & & $0.765 * * *$ & 0.021 & & & $0.785 * * *$ & 0.022 \\
\hline$(\text { Age })^{2}$ & & & $0.910 * * *$ & 0.011 & & & $0.907 * * *$ & 0.011 \\
\hline$(\text { Age })^{3}$ & & & $1.058 * * *$ & 0.010 & & & $1.056 * * *$ & 0.010 \\
\hline Children (reference: No children below 17) & & & & & & & & \\
\hline 1 child, youngest 2-5 yrs. & & & $1.656 * * *$ & 0.119 & & & $1.656 * * *$ & 0.119 \\
\hline 1 child, youngest $6-11$ yrs. & & & $1.244 *$ & 0.118 & & & $1.244 *$ & 0.117 \\
\hline 1 child, youngest $12-16$ yrs. & & & 1.103 & 0.074 & & & 1.095 & 0.074 \\
\hline 2 children, youngest 2-5 yrs. & & & $1.697 * * *$ & 0.105 & & & $1.674 * * *$ & 0.103 \\
\hline 2 children, youngest $6-11$ yrs. & & & $1.236 * *$ & 0.082 & & & $1.229 * *$ & 0.080 \\
\hline 2 children, youngest $12-16$ yrs. & & & 1.156 & 0.102 & & & 1.151 & 0.101 \\
\hline 3 or more children, youngest $2-5$ yrs. & & & $1.630 * * *$ & 0.134 & & & $1.593 * * *$ & 0.130 \\
\hline 3 or more children, youngest $6-11$ yrs. & & & 1.168 & 0.130 & & & 1.157 & 0.129 \\
\hline 3 or more children, youngest $12-16$ yrs. & & & 0.920 & 0.283 & & & 0.938 & 0.294 \\
\hline Level of education (reference: Lower second & r less) & & & & & & & \\
\hline Some upper secondary & & & $0.884 *$ & 0.051 & & & 0.895 & 0.052 \\
\hline Completed upper secondary & & & $0.878 * *$ & 0.036 & & & $0.887 * *$ & 0.037 \\
\hline Some post-secondary & & & $0.856 *$ & 0.063 & & & 0.921 & 0.069 \\
\hline Bachelor level & & & $0.789 * * *$ & 0.034 & & & $0.857 * *$ & 0.045 \\
\hline Master level & & & $0.697 * * *$ & 0.040 & & & $0.848 *$ & 0.064 \\
\hline PhD level & & & $0.531 * *$ & 0.100 & & & 0.793 & 0.158 \\
\hline
\end{tabular}

No. of employees (reference: 10 or less)

\begin{tabular}{|c|c|c|c|c|c|c|}
\hline $11-19$ & & & & $1.109 *$ & $0.0551 .104 *$ & 0.055 \\
\hline $20-49$ & & & & $1.154 * *$ & $0.0521 .149 * *$ & 0.052 \\
\hline $50-99$ & & & & $1.138 *$ & $0.0591 .134 *$ & 0.059 \\
\hline 100-199 & & & & $1.308 * * *$ & $0.0731 .305 * * *$ & 0.072 \\
\hline 200 or more & & & & 1.065 & 0.0511 .080 & 0.051 \\
\hline$>10$, exact number unknown & & & & 1.123 & 0.0941 .101 & 0.091 \\
\hline ailed occupation & no & no & & yes & yes & \\
\hline gree of urbanization & no & yes & & yes & yes & \\
\hline nstant & $0.012 * * * 0.000$ & $0.016 * * *$ & 0.000 & $0.013 * * *$ & $0.0020 .012 * * *$ & 0.002 \\
\hline respondents) & 55458 & 55458 & & 55458 & 55458 & \\
\hline observations) & 241653 & 241653 & & 241653 & 24165 & 53 \\
\hline
\end{tabular}

Note: To avoid an excessive number of zeros, age is measured in units of ten years. It is also centered around 40 years. Significance probabilities: $*<.05 ; * *<.01 ; * * *<.001$. Coefficients for Degree of urbanization are in Table A2 in the online appendix. 
Table 3. Poisson regression of long-term absence on sector of employment and different sets of control variables.

Exponentiated coefficients and their standard errors.

\begin{tabular}{|c|c|c|c|c|c|c|c|c|}
\hline & \multicolumn{2}{|c|}{ Model 1} & \multicolumn{2}{|c|}{ Model 2} & \multicolumn{2}{|c|}{ Model 3} & \multicolumn{2}{|c|}{ Model 4} \\
\hline & $\mathrm{b}$ & se & $\mathrm{b}$ & se & $\mathrm{b}$ & se & $\mathrm{b}$ & se \\
\hline Public sector & $1.255 * * *$ & 0.028 & $1.154 * * *$ & 0.027 & $1.083 *$ & 0.038 & 1.011 & 0.036 \\
\hline Woman & & & $1.583 * * *$ & 0.045 & & & $1.649 * * *$ & 0.058 \\
\hline Age (10-year units) & & & 1.003 & 0.023 & & & 1.033 & 0.024 \\
\hline$(\text { Age })^{2}$ & & & $0.954 * * *$ & 0.010 & & & $0.946 * * *$ & 0.010 \\
\hline$(\text { Age })^{3}$ & & & $1.070 * * *$ & 0.008 & & & $1.071 * * *$ & 0.008 \\
\hline \multicolumn{9}{|l|}{ Children (reference: No children below 17) } \\
\hline 1 child, youngest 2-5 yrs. & & & $2.293 * * *$ & 0.131 & & & $2.310 * * *$ & 0.130 \\
\hline 1 child, youngest $6-11$ yrs. & & & 1.144 & 0.084 & & & $1.153 *$ & 0.083 \\
\hline 1 child, youngest $12-16$ yrs. & & & 1.005 & 0.049 & & & 1.008 & 0.049 \\
\hline 2 children, youngest 2-5 yrs. & & & $1.366 * * *$ & 0.083 & & & $1.385 * * *$ & 0.083 \\
\hline 2 children, youngest $6-11$ yrs. & & & $1.127 *$ & 0.065 & & & $1.139 *$ & 0.065 \\
\hline 2 children, youngest $12-16$ yrs. & & & 1.021 & 0.073 & & & 1.033 & 0.074 \\
\hline 3 or more children, youngest 2-5 yrs. & & & 1.021 & 0.097 & & & 1.006 & 0.096 \\
\hline 3 or more children, youngest $6-11$ yrs. & & & 0.895 & 0.092 & & & 0.879 & 0.089 \\
\hline 3 or more children, youngest $12-16$ yrs. & & & 1.069 & 0.225 & & & 1.058 & 0.221 \\
\hline \multicolumn{9}{|c|}{ Level of education (reference: Lower secondary or less) } \\
\hline Some upper secondary & & & $0.823 * * *$ & 0.032 & & & $0.866 * * *$ & 0.034 \\
\hline Completed upper secondary & & & $0.728 * * *$ & 0.023 & & & $0.767 * * *$ & 0.025 \\
\hline Some post-secondary & & & $0.524 * * *$ & 0.036 & & & $0.655 * * *$ & 0.046 \\
\hline Bachelor level & & & $0.510 * * *$ & 0.017 & & & $0.594 * * *$ & 0.026 \\
\hline Master level & & & $0.313 * * *$ & 0.018 & & & $0.435 * * *$ & 0.033 \\
\hline PhD level & & & $0.234 * * *$ & 0.052 & & & $0.366 * * *$ & 0.091 \\
\hline
\end{tabular}

No. of employees (reference: 10 or less)

\begin{tabular}{|c|c|c|c|c|c|c|c|}
\hline $11-19$ & & & & 1.017 & 0.041 & 1.047 & 0.042 \\
\hline $20-49$ & & & & 1.036 & 0.039 & 1.072 & 0.040 \\
\hline $50-99$ & & & & 1.048 & 0.044 & 1.073 & 0.045 \\
\hline $100-199$ & & & & 1.056 & 0.050 & 1.081 & 0.051 \\
\hline 200 or more & & & & $1.084 *$ & 0.044 & $1.125 * *$ & 0.045 \\
\hline$>10$, exact number unknown & & & & 1.048 & 0.065 & $1.130 *$ & 0.070 \\
\hline ailed occupation & no & no & & yes & & yes & \\
\hline ree of urbanization & no & yes & & yes & & yes & \\
\hline stant & $0.041 * * * \quad 0.001$ & $0.033 * * *$ & 0.001 & $0.078 * * *$ & 0.006 & $0.056 * * *$ & 0.006 \\
\hline espondents) & 56189 & 56189 & & 56189 & & 5618 & \\
\hline bservations) & 252153 & 252153 & & 25215 & & 25215 & \\
\hline
\end{tabular}

Note: To avoid an excessive number of zeros, age is measured in units of ten years. It is also centered around 40 years.

Significance probabilities: *<.05; **<.01; ***<.001. Coefficients for Degree of urbanization are in Table A3 in the online appendix. 
Table 4. Selected results from Poisson regression of short-term and long-term absence on sector, stable employment in one sector only (non-switcher), the interaction of these variables, and control variables.

Short-term absence Long-term absence

Public sector

b

se $\quad b$

se

Non-switcher

$\begin{array}{llll}1.100 & 0.104 & 0.807 * * & 0.067\end{array}$

Public sector * Non-switcher

0.897

$0.0650 .819 * * \quad 0.052$

Constant

$1.219 \quad 0.117 \quad 1.398 * * * \quad 0.118$

$\mathrm{N}$ (respondents)

$0.013 * * * \quad 0.003 \quad 0.056 * * * \quad 0.006$

$\mathrm{N}$ (observations)

41317

41739

Note: The control variables are the same as in Tables 2 and 3. Full results in Table A4 in the online appendix.

Significance probabilities: $*<.05$; $* *<.01 ; * * *<.001$. 
Figure 1. Estimated relative differences in short-term and long-term absence for employees in the public sector compared with the private sector. Separate estimates for sector switchers and non-switchers. Based on coefficient estimates in Table 4. 95\% confidence intervals.

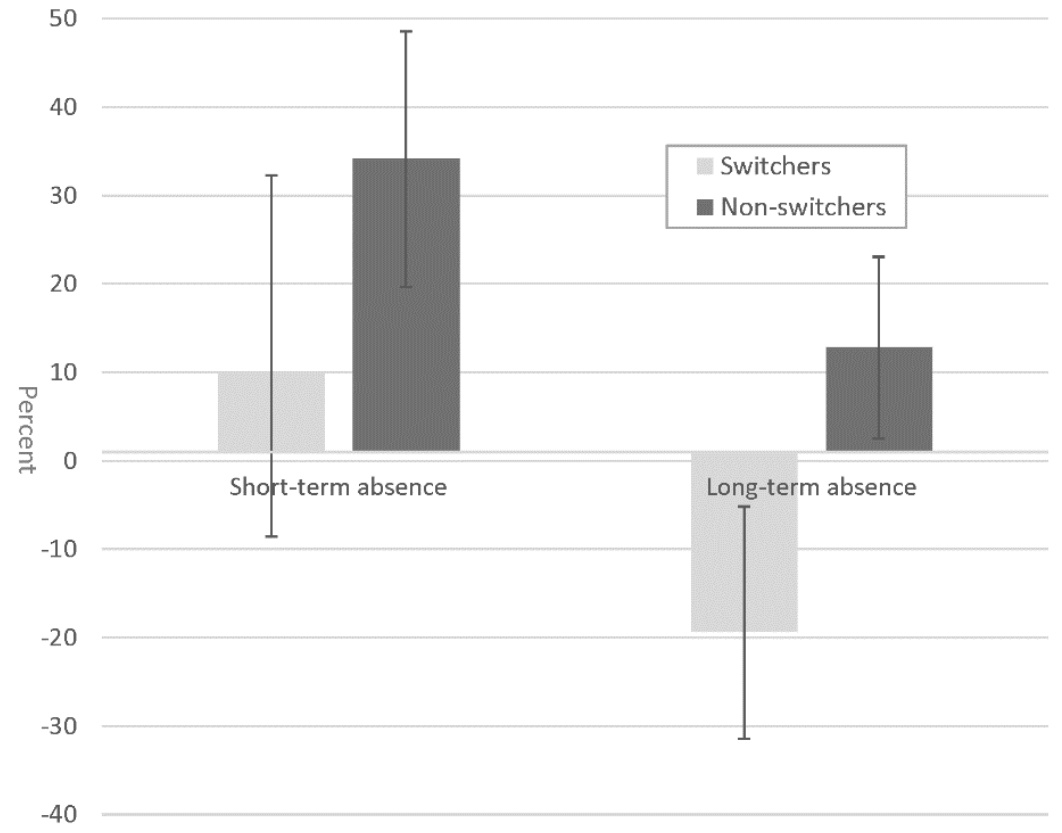

